MSCRA

4,2

86

Received 15 January 2022

Revised 16 February 2022

Accepted 21 February 2022

\title{
Platform opening and cooperation: a literature review and research agenda
}

\author{
Weihua Liu and Yanjie Liang \\ College of Management and Economics, Tianjin University, Tianjin, China \\ Xiaoran Shi \\ College of Management and Economics, Tianjin University, Tianjin, China and \\ School of Management, Tianjin University of Technology, Tianjin, China \\ Peiyuan Gao \\ College of Management and Economics, Tianiin University, Tianjin, China, and \\ Li Zhou \\ Systems Management and Strategy Department, Business School, \\ University of Greenwich, London, UK
}

\begin{abstract}
Purpose - The review aims to facilitate a broader understanding of platform opening and cooperation and points out potential research directions for scholars.

Design/methodology/approach - This study searches Web of Science (WOS) database for relevant literature published between 2010 and 2021 and selects 86 papers for this review. The selected literature is categorized according to three dimensions: the strategic choice of platform opening and cooperation (before opening), the construction of an open platform (during opening) and the impact of platform opening and cooperation (after opening). Through comparative analysis, the authors identify research gaps and propose four future research agendas.

Findings - The study finds that the current studies are fragmented, and a research system with a theoretical foundation has not yet formed. In addition, with the development of platform operations, new topics such as platform ecosystems and open platform governance have emerged. In short, there is an urgent need for scholars to conduct exploratory research. To this end, the study proposes four future research agendas: strengthen basic research on platform opening and cooperation, deeply explore the dynamic evolution and cutting-edge models of platform opening and cooperation, analyze potential crises and impacts of platform openness and strengthen research on open platform governance.

Originality/value - This is the first systematic review on platform opening and cooperation. Through categorizing literature into three dimensions, this article clearly shows the research status and provides future research avenues.
\end{abstract}

Keywords Platform opening, Platform cooperation, Co-opetition, Research agenda

Paper type Research paper

\section{Introduction}

With the development of the mobile Internet, the platform has a significant impact on the economy. Pricewaterhouse Coopers reports that various platforms will generate $\$ 335$ billion

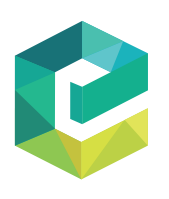

Modern Supply Chain Research and Applications Vol. 4 No. 2, 2022 pp. $86-104$ Emerald Publishing Limited 2631-3871 DOI 10.1108/MSCRA-01-2022-0001
(C) Weihua Liu, Yanjie Liang, Xiaoran Shi, Peiyuan Gao and Li Zhou. Published in Modern Supply Chain Research and Applications. Published by Emerald Publishing Limited. This article is published under the Creative Commons Attribution (CC BY 4.0) licence. Anyone may reproduce, distribute, translate and create derivative works of this article (for both commercial and non-commercial purposes), subject to full attribution to the original publication and authors. The full terms of this licence may be seen at http:// creativecommons.org/licences/by/4.0/legalcode

This research is supported by Major Program of the National Social Science Foundation of China (Grant No. 18ZDA060). The reviewers' comments are also highly appreciated.

This paper forms part of a special section "Managing Platform-based Supply Chains in the Digital Era: Lessons after Post-Pandemic", guest edited by Gongbin Bi, Jianbin Li, Weihua Liu, Xiaoping Xu and Xiaoran Shi. 
in revenue worldwide by 2025 (Federal Trade Commission, 2016). Following European Commission (2017), the online platform can be defined as a digital marketplace that enables buyers and sellers to effectively search, match and trade through various Internet-connected digital communication devices. Examples include e-commerce platforms (e.g. Amazon, Alibaba) and ride-sharing platforms (e.g. Uber, Didi). By providing interactive media, the platform not only creates value for different users but also obtains benefits.

In practice, many platforms have recently implemented opening and cooperation strategies, which injects new impetus into the development of the platform. For instance, in the ecommerce market, JD.com displays product sales links on Tiktok to expand the potential market. Thus, users in Tiktok can directly enter the JD.com's applet embedded in Tiktok to purchase (Liu et al., 2021a). Similar cooperation also appears in the ride-sharing platform. In 2014, Uber was already compatible with the local taxi platform in Seattle. In this case, passengers can select multiple options (UberX, UberXL, Black Car, SUV and For Hire) directly from the Uber app (Cohen and Zhang, 2017). In 2019, Didi allowed rivals such as Dongfeng and Ruqi to access its own platform (Sohu News, 2019).

In academia, massive studies focus on operations in the monopoly platform and competitive platform (Chou et al., 2012; Kung and Zhong, 2017; Armstrong, 2006; Bakos and Halaburda, 2020). Nowadays, platform opening and cooperation have aroused the interest of more scholars. Some studies point out the importance of platform opening and cooperation. Van Alstyne et al. (2016) argue that platforms often fail because they do not optimize openness: "If platforms are too closed, keeping potentially desirable participants out, network effects stall; if they're too open, there can be other value-destroying effects, such as poor quality contributions or misbehavior of some participants that causes others to defect." Cooperation between the platform and other business entities can achieve a win-win situation (Liu et al, 2021a). To this end, scholars' attention to platform opening and cooperation has led to a series of academic research, including platform compatibility, channel integration in e-commerce market, the impact of platform opening and so on.

In summary, scholars have reached a consensus on the importance of platform opening and cooperation research; however, scholars in various fields emphasize different concerns. For example, scholars in the field of operation management and business pay attention to how to achieve a win-win situation through cooperation (Fan et al., 2020; Zhu et al., 2021). In contrast, some studies in the field of information systems explore the possible impact and outcome of platform opening (Ondrus et al., 2015; Wessel et al., 2017; Song et al., 2020). The difference in terms (cooperation and opening) has led to a large number of relevant studies that have not been inspired by each other. Therefore, it is very complicated to integrate different research fields' insights on platform opening and cooperation. However, it provides a great opportunity to enhance our understanding of this platform operation trend and helps scholars clarify research gaps and focus on more valuable research fields. Therefore, we are motivated to conduct a systematic and comprehensive literature review of the platform opening and cooperation. Based on the understanding of research topics, we also emphasize several key areas for future research and make detailed suggestions for different research areas. To the best of our knowledge, this is the first literature review on platform cooperation and opening.

\section{Methodology}

When conducting a literature review, certain steps need to be followed to ensure the reliability of the review results. The general method of reviewing the literature follows three steps: (1) planning the review, (2) conducting the review and (3) reporting and disseminating (Tranfield et al., 2003). The detailed process is summarized in Figure 1.

\subsection{Planning the review}

We form a review panel consisting of two researchers to avoid individual bias. The panel agree on some original keywords for review: platform openness, platform opening, platform 


\section{MSCRA}

4,2

\section{8}

Figure 1.

Overview of the literature review process

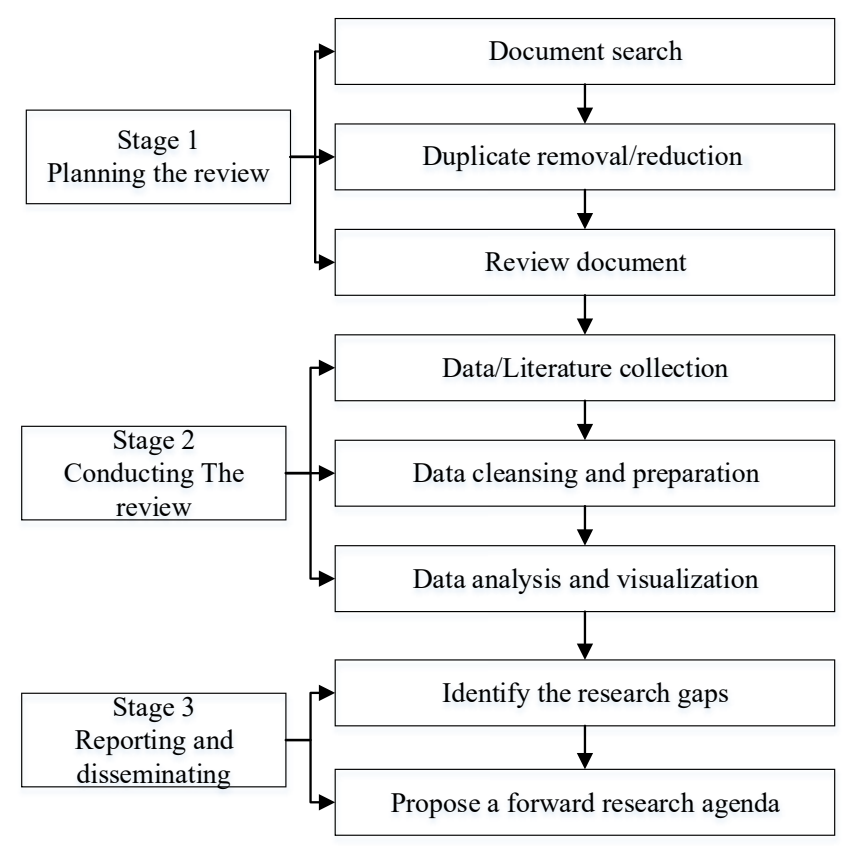

cooperation, platform co-opetition, channel open, channel cooperation, online channel integration, online channel coordination and so on. Based on these keywords, the panel develop an initial review document and conduct a preliminary search on several well-known databases such as Web of Science (WOS), Wiley, Emerald, Taylor and Francis and Science Direct. The search scope is limited to articles and reviews written in English, but does not impose any restrictions on the publication date. Finally, the panel evaluate the relevance of results by reviewing abstracts and adjusting keywords accordingly. After preliminary search, we find that some keywords (such as online channel coordination.) do not accurately capture the research topic, so the panel adjusts them. Since about $90 \%$ of the results of Wiley, Emerald, Taylor and Francis and Science Direct overlapped with those searched in WOS, and WOS provided more results, the panel select WOS as the final review database.

In addition, we find that since 2010, the topic on platform opening and cooperation is favored by top journals, such as Management Science and Journal of Management Information Systems. Additionally, the number of research publications before 2010 is limited; thus, the panel defines time span as 2010-2021. After conducting three preliminary searches, validating the search results and adjusting the review document, the panel reach an agreement on the document, as shown in Table 1. It is worth mentioning that this study does not involve the review of technical research on platform opening, such as open software design and compatible platform development. In other words, literature on the design and development of open platforms is excluded.

\subsection{Conducting the review}

In this subsection, we show the details of conducting the review, including data/literature collection, data cleansing and preparation, data analysis and data visualization.

2.2.1 Data/literature collection. In November 2021, the two members of the review panel conducted independent formal searches based on the review document. We do not limit the 


\begin{tabular}{ll}
\hline Dimensions & Contents \\
\hline Keywords & $\begin{array}{l}\text { Platform openness, platform opening, platform cooperation, platform co-opetition, channel } \\
\text { open, channel cooperation, online channel integration }\end{array}$ \\
Search scope & Title, keywords and abstract of the paper \\
Period & 2010-2021 \\
Inclusion & Platform open/cooperation strategies \\
criteria & Platform open/cooperation business model \\
& Platform/channel integration and collaboration \\
Exclusion & Co-opetition between platforms and manufacturers/retailers \\
criteria & Compatible platform development \\
Type of source & Articles; reviews \\
Language & English \\
Database & WOS
\end{tabular}

journal so as not to omit some research work that has innovative ideas but has not been published in high-level journals. The initial search result is 164 papers in the database. The article selection process is illustrated in Figure 2.

2.2.2 Data cleansing and preparation. According to the screening criteria in Table 1, 71 papers are excluded and 84 papers are retained. For example, Niu et al. (2021) include "platform" and "cooperation" in the title and abstract. However, they explore restaurant's strategic choice for platform logistics and self-operated logistics, which is not relevant to the review topic of this study. After the independent screening, panel members had different opinions on the judgment of the 9 papers. After reading the full text, two of them are included, and the remaining 7 are excluded. For instance, Bahar et al. (2022) study the co-opetition relationship between platforms and hotel service providers. However, after further reading, we find that this research focuses on how hotel service providers deal with co-opetition with the platform, so this paper is excluded. Finally, we select 86 papers consistent with the topic as the basis for the review. Such a structured process and careful screening help in achieving objectivity and reliability in this research (Hahn and Kühnen, 2013).

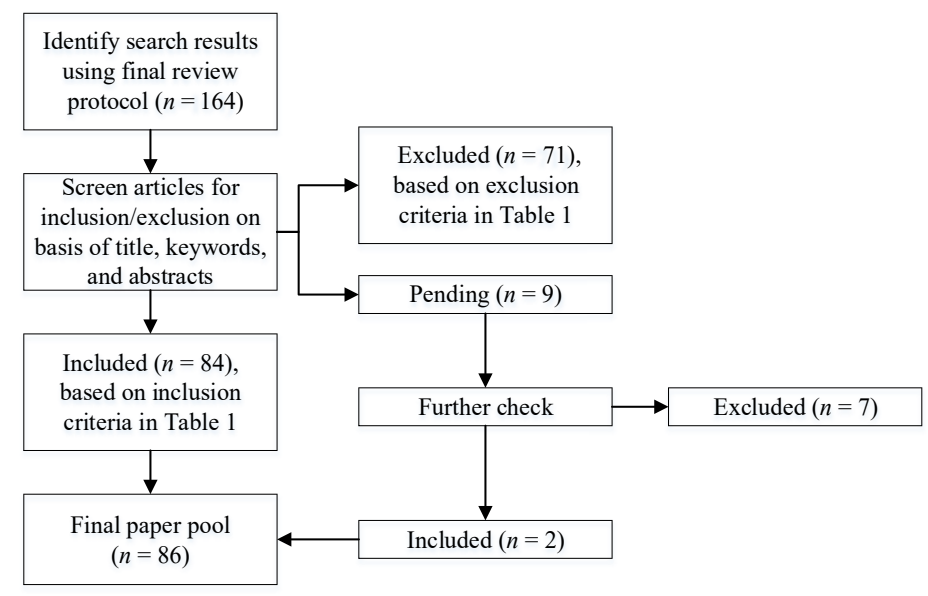

Figure 2. Article selection process 
MSCRA

4,2

90
2.2.3 Data analysis and visualization. Tranfield et al. (2003) believe that the data analysis of literature review can be divided into two parts: one is a full "descriptive analysis" of the field using a simple or visual set of categories, and the other is a "thematic analysis" derived through an aggregative or interpretative approach. The details of descriptive analysis and thematic analysis are shown in Section 3 and Section 4, respectively. In order to better sort out the above-mentioned literature, we have collected information about article titles, journal titles, authors, publication dates and abstracts. Additionally, through internal discussions, panel members also record some additional information, such as research questions, research methods and research objects.

\subsection{Reporting and disseminating}

After conducting a literature review, we aim to identify research gaps on this topic and propose some potential research agendas based on practical and academic frontiers. For the topic categories and research gaps that were sorted out, panel members should provide a detailed audit trail back to the core contributions to justify and ground their conclusions. Linking themes across the various core contributions wherever possible and highlighting such links are important parts of the reporting process (Tranfield et al., 2003).

\section{Descriptive analysis}

As shown in Figure 3, two papers related to platform opening and cooperation topics are published in 2010, including Boudreau (2010) published in Management Science and Lahiri et al. (2010) published in the Journal of Management Information Systems. With the innovation of platform operations, discussions on openness and cooperation have grown rapidly in recent years. We find that the number of publications in 2020 and 2021 reached 50, accounting for about $60 \%$ of the total publications. Therefore, platform opening and cooperation are becoming a potential and attractive research topic.

We categorize journals in which the articles are published. It can be seen from Figure 4 that these journals involve different research fields, mainly including operations management (45 papers), business (16 papers), economics (11 papers) and information systems (10 papers). Among them, operation management journals account for more than half, which involve e-commerce platforms (Liu et al., 2021a; Qin et al., 2020), two-sided platforms (Zhu et al., 2021), luxury rental platforms (Feng, 2020) and so on. A few information

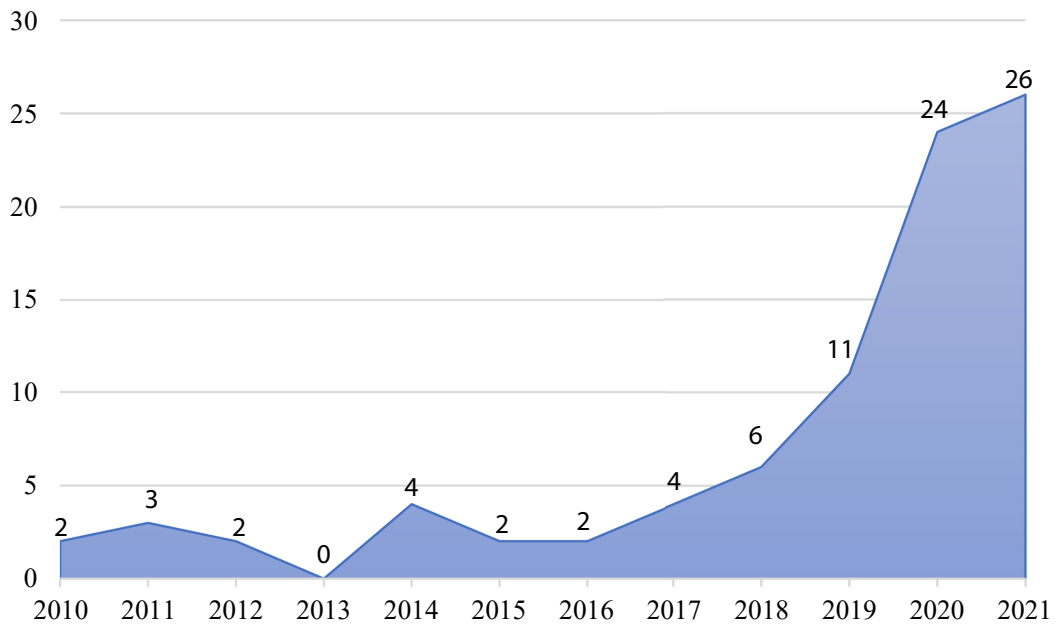

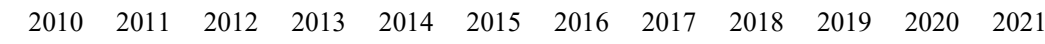

Figure 3.

Number of publications by year 


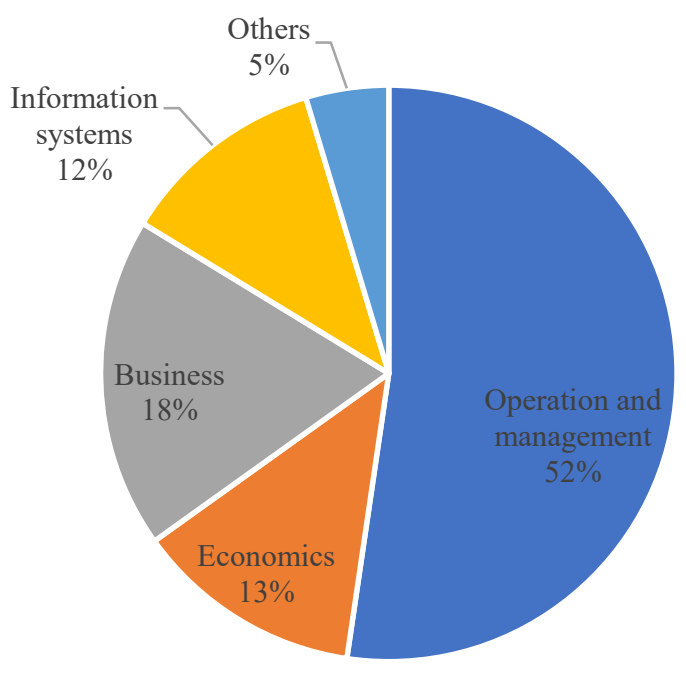

Platform opening and cooperation

system journals focus on similar objects, but mainly involve software compatibility (Geng et al., 2021) and access to third-party platforms (Tan, 2020; Song et al., 2020).

Figure 5 shows the most active journals in this research field. We find that not only some high-level journals such as Electronic Commerce Research and Applications, Transportation Research Part E: Logistics and Transportation Review, Journal of Business Research, International Journal of Production Economics and Industrial Marketing Management, but also some top journals, such as Management Science and Information Systems Research, also favor the topic of platform opening and cooperation. It shows that this topic has become one of the important research trends.

Figure 6 shows the research methodology used in this topic. We find that this topic involves a variety of methods, which also reflects the flexibility and breadth of research on this topic. Specifically, most scholars use mathematical models to focus on strategic or operational decisions. Some researchers use empirical research to explore the impact of

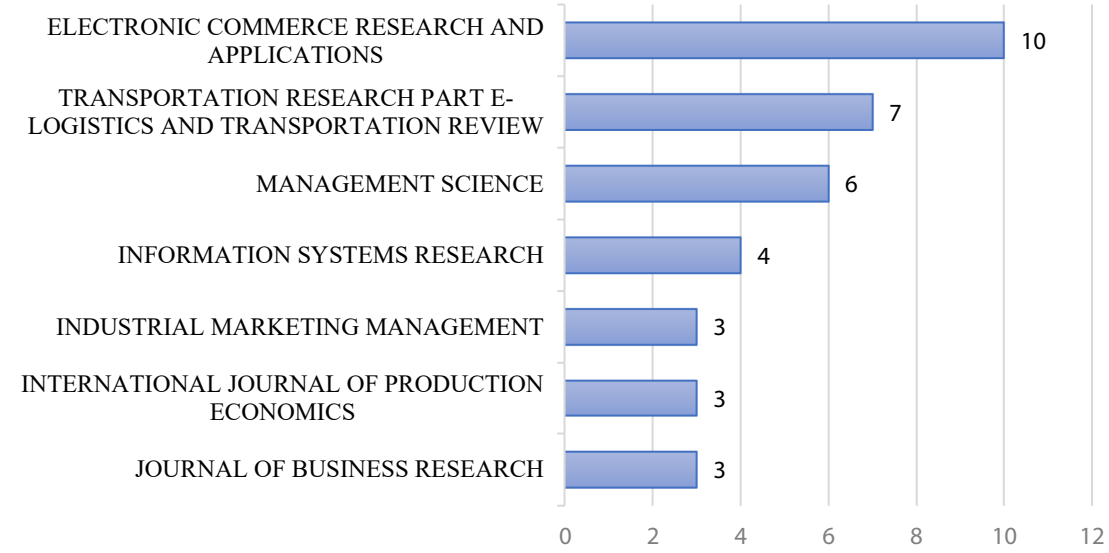

Figure 5. Journals active in this field research fields 


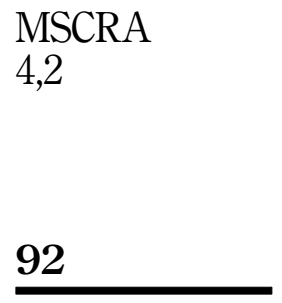

Figure 6.

Distribution of research method

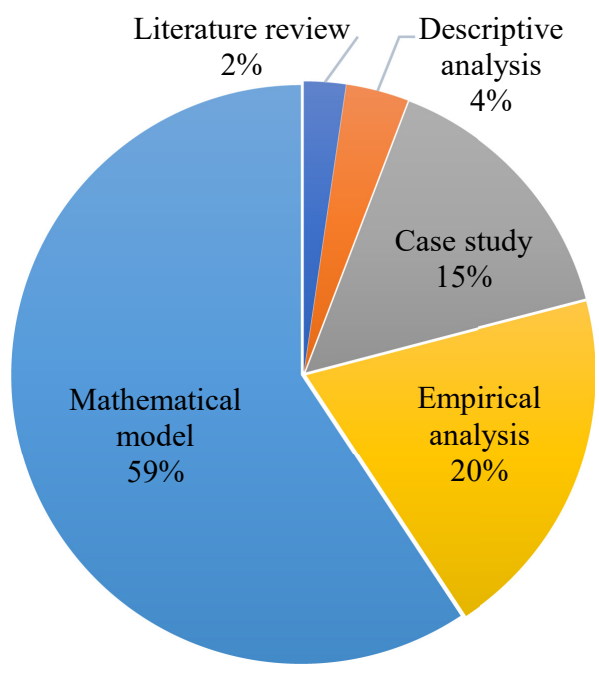

platform opening on company performance. In addition, some studies have tried to provide theoretical support for platform opening and cooperation based on a single case or multiple cases. Finally, a few scholars use descriptive analysis and literature review to explain the concept and connotation of platform opening and cooperation.

In addition, we summarize the keywords of 86 articles, as shown in Figure 7. The most frequent keywords are platform openness, e-commerce platform, digital platforms, cooperation, two-sided platform, co-opetition, compatibility, supply chain, network, platform sharing and so forth. These keywords reflect not only research topics such as platform opening, co-opetition and cooperation, cooperation and compatibility but also research objects such as e-commerce platforms, two-sided platforms and digital platforms, which provide ideas for the following research direction.

\section{Thematic analysis}

In fact, 86 articles have involved a variety of research topics and methods. For the scientific category literature, we review the full text of each article and record the motivation, problem,

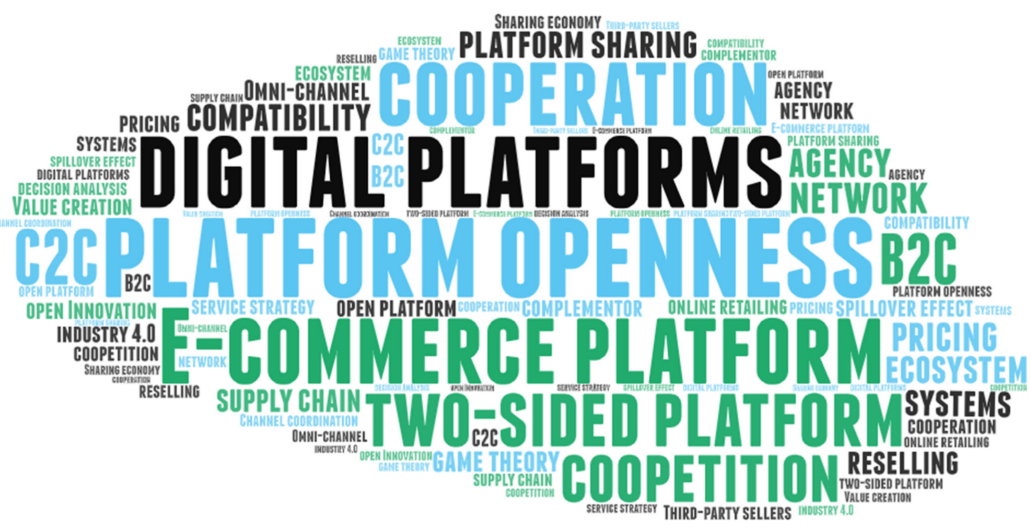

Figure 7.

Word cloud map most frequent keywords 
contribution, audience, timing, location and methods of the papers (Yoshioka et al., 2001). On this basis, we identify three main research themes: the strategic choice of platform opening and cooperation (i.e. before opening, 41 papers), the construction of an open platform (i.e. during opening, 23 papers) and the impact of platform opening and cooperation (i.e. after opening, 22 papers).

We further refine the subthemes, as shown in Figure 8. To be specific, the first and most important theme is the strategic choice of platform opening and cooperation, and nearly half of the studies have been developed around it. Researchers mainly focus on two types of platforms: e-commerce platforms represented by Amazon.com, Tmall.com and JD.com, and two-sided (matching) platforms represented by Uber, Didi and Airbnb. In addition, a few studies analyze sharing platforms (Ren, 2020), luxury fashion rental platforms (Feng, 2020) and so forth. Second, regarding the construction of an open platform, some scholars concern the capabilities that the open platform should have, including driving factors and operating modes; the remaining scholars pay attention to how the platform should work with other members to achieve value co-creation through collaborative opening. Finally, the impact of platform opening and cooperation has also been systematically investigated. Specifically, platform opening and cooperation will not only change the decision-making and performance of stakeholders but also affect non-economic indicators, such as innovation and customer satisfaction.

It is worth noting that, in the process of sorting out themes, the above-mentioned themes are not independent of each other, but are related. For example, some scholars discuss the impact of platform opening and cooperation on stakeholders when exploring their strategic choices (Huang and Jin, 2020; Liu et al., 2021a; Geng et al., 2021). Some scholars refer to practical cases from e-commerce or two-sided platforms when investigating the cooperation mechanism of platforms (Ritala et al., 2014; Hilbolling et al., 2020). In summary, through the above framework, we have a general understanding of research on platform opening and cooperation. Next, we will introduce the research progress of each theme in detail.

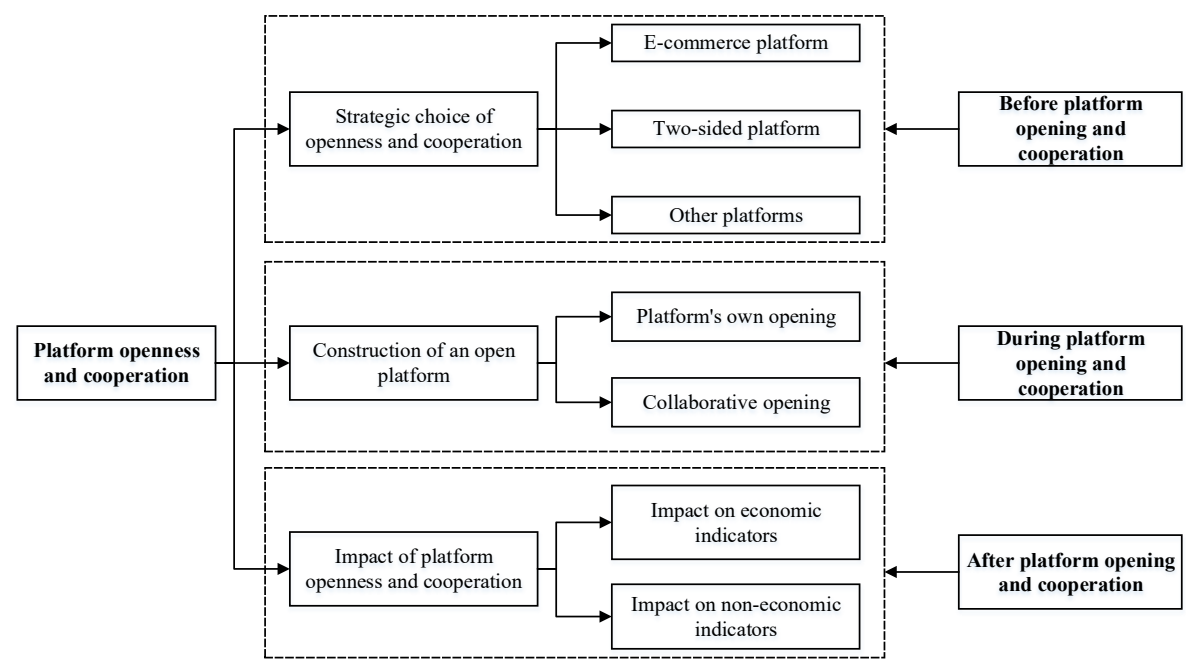

Platform opening and cooperation
Figure 8.

Research themes of platform opening and cooperation 
MSCRA

4,2

94

\section{Detailed analysis of platform opening and cooperation}

\subsection{Strategic choice of platform opening and cooperation}

There are 41 papers focusing on this topic, accounting for almost half of 86 papers. From the perspective of research methods, mathematical analysis, more precisely, game theory is the most popular method, followed by empirical analysis. From the perspective of research objects, e-commerce platforms (22 papers) and two-sided platforms (12 papers) account for the majority of total papers, and the remaining papers focused on other types of platforms or do not specify the types of platforms (8 papers).

5.1.1 E-commerce platforms. In the research related to e-commerce platforms, most scholars pay attention to channel integration. Some scholars capture the integration between online platforms and offline channels, that is, omnichannel retailing, which refers to a business model that provides a seamless shopping experience for customers through a retailer's coordination of both the platform and physical store channels (He et al., 2020, 2021; Liu et al., 2020a; Huang and Jin, 2020; Zhang et al., 2021a). For example, He et al. (2020) explore the impact of competition intensity on the buy-online-and-deliver-from-store (BODS) strategy, which means that manufacturers sell products through both online and offline channels, and hire offline retailers to deliver online orders from their warehouses. Similarly, He et al. (2021) find that the ship-from-store option can provide time-sensitive consumers with a quick logistics service and explore the conditions under which online retail platforms benefit from this option. In addition, scholars take product returns into consideration. For example, Huang and Jin (2020) capture the phenomenon of retailers setting up buy-onlineand-return-in-store (BORS) services.

Some scholars study the issue of channel opening between e-commerce platforms. As we all know, e-commerce platforms have two operating modes: reselling and agency selling (Abhishek et al., 2016). In fact, scholars have conducted extensive research on the competition between the two modes (Hsiao and Chen, 2013; Abhishek et al., 2016; Tian et al., 2018). However, in recent years, the phenomenon of hybrid retailing has begun to attract attention, which refers to the integration of resources to expand the product lines between e-commerce platforms with different operating modes (Li et al., 2019). For example, Fan et al. (2020) focus on the agency mode platform (e.g. Tmall.com) allowing the reselling mode platform (e.g. Suning.com) to establish flagship stores on its own platform. In contrast, Song et al. (2020) explore the phenomenon that platforms that adopt the agency model are open to third-party sellers who adopt the reselling model.

Additionally, a few scholars have explored the cooperation between e-commerce platforms and non-e-commerce platforms. Liu et al. (2021a) focus on the cooperation between e-commerce platforms and social service platforms such as Tiktok and Meiyou, and analyze the influence of market power on their willingness to cooperate. Qin et al. (2020) analyze the conditions for e-commerce platforms to share logistics systems with third-party sellers.

5.1.2 Two-sided platforms. Two-sided platforms often have the attribute of network externality. Specifically, through this intermediate connection, the utility of one group of users (or agents) will be affected by that of another group of users (Zhu et al., 2021). Regarding the opening and cooperation in two-sided platforms, the core of scholars' concern is compatibility, which refers to the co-opetition relationship formed after platform owner hosts a rival's application/software (Mantena and Saha, 2012; Maruyama and Zennyo, 2015; Lu et al., 2019; Adner et al., 2020; Hagiu et al., 2020). Mantena and Saha (2012) investigate how technological asymmetry affects the motivation for platform compatibility. Results show that technological improvements on disadvantaged platforms will not significantly increase their profits but will reduce the opportunities for cooperation. Lu et al. (2019) study the compatibility strategy selection under the cross-platform cost borne by the customer and the platform. Adner et al. (2020) take the compatibility between iPad and Kindle as an example, 
and explored the compatibility decision of platforms when they generate profits through both hardware sales and royalties from content sales. The research results show that the establishment of one-way compatibility may be derived from their different profit foci.

There are also some studies that have captured personalized cooperation in two-sided markets such as ride-hailing platforms. For example, regarding the phenomenon that taxihailing platforms cooperate with car rental companies, Lin et al. (2021) find that when the commission rate is high or the fixed payout ratio is low, cooperation can yield a win-win-win outcome for the platform, customers and drivers. Inspired by the cooperation between Meituan, a two-sided platform, and WeChat, a social media platform, Zhu et al. (2021) investigates the two-sided platform's scalable decisions on when to cooperate and how to optimize the pricing and investment decisions.

5.1.3 Other platforms. In addition to e-commerce platforms and two-sided platforms, some scholars pay attention to other types of platforms, such as industry platforms, operating system platforms and luxury rental platforms (Tsai, 2018; Ren et al., 2020; Hagiu et al., 2020; Feng et al., 2020). For instance, Tsai (2018) analyzes antecedent of industry platform emergence and clarifies the suitable timing of increasing platform openness. Ren et al. (2020) investigate the coordination between a manufacturer and rental sharing platform in the context of recycling and non-recycling. Feng et al. (2020) study the impact of product sharing platform on luxury fashion brands and reveal that the presence of a rental platform leads to two simultaneous effects: a market expansion effect and a cannibalization effect.

\subsection{Construction of open platform}

In this research field, the path and the mode of platform opening are the core concerns. At present, this topic involves 23 papers with various research methods, most of which are case studies and empirical analysis, and a few are literature review and descriptive analysis. In terms of research content, 8 papers explore the own opening of the platform, while 15 papers focus on collaborative opening.

5.2.1 Platform's own opening. Regarding the platform's own opening, some researchers have explored the drive and capabilities of opening. Through a case study, Abbate et al. (2019) extract the methods that companies use open innovation digital platforms (OIDP) to effectively explore, acquire, integrate and develop valuable knowledge. They point out that OIDP is the "co-creator intermediaries" that define, develop and implement dedicated processes, specific tools and appropriate services for supporting knowledge co-creation activities. Broekhuizen et al. (2021) believe that platform openness results from a series of decisions on how to open a platform are regarding (1) suppliers, (2) customers, (3) complementary service providers, (4) product categories and (5) channels. On this basis, they explore the drivers, dimensions and outcomes of platform openness. Abbate et al. (2021) put forward the required capabilities of an open innovative digital platform through a literature review. They develop a theoretical framework and advance propositions by underlining the specific required dynamic capabilities: sensing, seizing, scanning, integrating and transformative.

Some scholars identify the path and mechanism of platform opening. Karhu et al. (2018) propose an exploitative and competitive platform strategy: platform forking, in which a hostile firm, that is, a forker, bypasses the host's controlling boundary resources and exploits the platform's shared resources, core and complements to create a competing platform business. Zhu and Liu (2018) empirically analyze Amazon's entry pattern into third-party sellers' product spaces. They find Amazon is more likely to target successful product spaces, but is less likely to enter product spaces that require greater seller efforts to grow. Ma et al. (2020) explore the coordination between optimal crowdsourcing contracting strategy and reconfigurable process planning by a nesting genetic algorithm in an open manufacturing platform. 
MSCRA

4,2

96
5.2.2 Collaborative opening between the platform and other members. In terms of collaborative opening, some studies explore the interaction between platforms and stakeholders in logistics, manufacturing and other industries. Through a qualitative longitudinal (2005-2019) study of the global digital advertising ecosystem, Cozzolino et al. (2021) describe three steps for manufacturers to respond to platform opening and entry: (1) selective cooperation, (2) allied competition and (3) selective co-opetition. Liu et al. (2021b) use the evolutionary game to explore the trend of cooperation between logistics platforms and suppliers from the perspective of business ecology. Results show that the relationship between the agency fee, empowerment cost and service price elasticity coefficient determines the platform's ultimate evolutionary stable strategy. By exploring Facebook's integration of Instagram, Li and Agarwal (2017) study the impact of platform integration on consumer demand for the first-party application and the competing third-party application. They find that the growth of Instagram's user base has a positive spillover effect on big third-party applications but a negative spillover effect on small third-party applications. Mačiuliene and Skaržauskienè (2016) adopt a social indices calculation methodology to study the collaborative operation of 30 platforms in Lithuania. By setting up indicators such as the capacity for creativity, capacity for aggregating knowledge and capacity for decision making, they assess whether the collaboration platform has reached the goal of value co-creation.

There are also a few scholars using case studies to explore platform-based collaborative innovation. Esposito De Falco et al. (2017) analyze a case from TIM OPEN. Conclusions suggest that collaborative innovation based on digital platforms can reduce transaction costs. Hilbolling et al. (2020) investigate how platform owners manage open innovation to coordinate the development of diverse complementary products on their digital platform. Lee et al. (2020) study the four cooperation practices from the cultural and creativity-driven overthe-top (OTT) platform and reveal how co-innovative business ecosystems demonstrate co-evolution through different structures and directions.

\subsection{Impact of platform opening and cooperation}

There are 22 papers published in this field. From the perspective of research methods, empirical analysis, case studies and mathematical analysis are widely used. From the perspective of research content, 12 papers focus on the economic impact of platform opening and cooperation, and the remaining 10 papers focus on the impact on non-economic indicators.

5.3.1 Impact on economic indicators. Some studies use game theory to analyze how platform opening affects the economic decision-making (such as price and quantity decisions) and performance of stakeholders. Zhang et al. (2021b) describe the value creation and value appropriation of a B2B alliance in the implementation of cooperative advertising. They show that there is an unequal win-win situation in the alliance as the platform has a "free-ride" effect and always obtains more value from the manufacturer's full support for national brand advertising. Kong et al. (2020) analyze the effects of "buy online and pick up in store" on prices, demand and profits under the scenario of consistent and inconsistent pricing between online and offline channels, and explored whether the two cooperation mechanisms are beneficial to the retailing platform. Xiang and Xu (2019) establish a closed-loop supply chain consisting of a manufacturer, a retailer and a service platform, and explored the changes in the profit and goodwill of supply chain members in the retailer payment scenario and the manufacturer cost-sharing scenario, respectively. Gallino and Moreno (2014) investigate the impact of "buy-online, pick-up-in-store" (BOPS) on sales, and explained two phenomena caused by BOPS: cross-selling effect and channel-shift effect. Weber and Maier (2020) conduct a large field survey to confirm the positive effects of both forms of cross-channel 
delivery (delivery from the online shop to the store vs. delivery from the store to consumers' home) in reducing consumers' propensity to research shop competitively.

5.3.2 Impact on non-economic indicators. Platform opening and cooperation will also have an impact on non-economic indicators, such as innovation, market potential and organizational networks. For example, Boudreau (2010) captures two methods of platform opening - granting access versus devolving control - and analyzed their different impacts on innovation. By developing a conceptual analysis framework, Menon et al. (2020) describe the dimensions and subdimensions of platform openness, and thus explored the impact of platform openness on end-users and suppliers in the long/short term. Ondrus et al. (2015) explore how the openness of provider, technology and user levels will affect platform's market potential. To be specific, the provider level involves the strategic involvement of key stakeholders that provide a platform. The technology level is concerned with the interoperability of a platform across different technologies. The user level relates to what extent a platform discriminates different segments of the customer base. Wei et al. (2019) explore how customer solution providers leverage digital platform architectures and particularly platform openness to exert control over complex organizational networks. By managing platform openness of different subsystems accordingly, the solution providers can achieve different control benefits, including ensuring module quality, increasing offering variety, reducing dependence on module providers and facilitating resource sharing.

\section{Future research}

With the continuous development of the platform economy, there are still several research directions that need to be enriched in the field of platform opening and cooperation, which may generate valuable research findings. We first put forward some general research challenges in this field. On this basis, we propose four potential research agendas.

\subsection{General challenges of platform opening and cooperation research}

First, current research mainly focuses on several types of platforms whose features are easily captured, such as e-commerce and ride-hailing platforms. The operational challenges of some niche platforms, such as payment platforms (PayPal, Alipay), recruitment platforms (Kelly Services, Indeed) and medical platforms (ZocDoc, One Medical, Doctor On Demand), have not been thoroughly explored (Rietveld and Schilling, 2021). For example, the payment platform has transformed from a single payment function platform to a community-based platform, integrating multiple functions such as taxi-hailing and other living payments. In the meanwhile, some recruitment platforms develop the social module based on job search information matching, allowing users to discuss the company and expose job salaries.

In addition, the researchers' vision is limited to the current Internet giants, and has not been extended to other industrial backgrounds. In other words, the opening of platforms in other industries also needs the attention of scholars. For example, in the manufacturing industry, Haier's open platform COSMO-Plat plays an important role in promoting cooperation among supply chain members, which is worthy of in-depth analysis (Liu et al., 2020b). In the logistics industry, it is worth exploring how matching platforms, such as Full Truck Alliance, expand aftermarket services to compete with existing service providers. Furthermore, some navigation service platforms such as AutoNavi are integrating several competing ride-hailing platforms (such as Didi) in China. However, whether this phenomenon can improve consumer surplus has yet to be investigated.

Finally, the current research methods are limited, and a variety of methods should be used to solve research problems. In terms of the case study, few researchers use the longitudinal case study to reveal the driving mechanism of some empirical results, such as identifying the

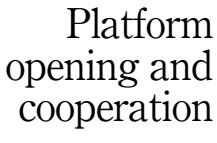


MSCRA

4,2

evolution path of the platform's value co-creation. In terms of empirical analysis, scholars can collect data samples from multiple countries to distinguish their platform opening and cooperation mechanisms. As far as the mathematical model is concerned, dynamic system theory and evolutionary games can be used to further analyze the evolution of platform opening and cooperation.

\section{8}

\subsection{Potential research agendas}

The current research on platform opening and cooperation is still driven by practical observation, which leads to fragmented topics in this field, and a rigorous research system has not yet been formed. Therefore, future research should focus on basic research, such as the connotation of platform opening (openness) and the path and mechanism of platform cooperation. In addition, with the development of platform operations, new phenomena have emerged, such as platform ecosystems and open platform governance. In summary, we propose the following four potential research directions.

6.2.1 Basic research on platform opening and cooperation. The basic research on platform opening and cooperation is worthy of attention. First, existing studies believe that opening and cooperation have become the trend of platform development and provide massive practical cases. However, the connotation of platform opening and cooperation is still not clearly defined. For example, compared with traditional enterprises, what are the characteristics of platform opening, and what are the motivations for platform cooperation? Therefore, future research needs to explore the more precise concept of platform opening and cooperation in multiple dimensions such as organization, technology and operation based on data and cases. Second, future research can design the measurement indicators of platform openness. Menon et al. (2020) put forward some dimensions for platform openness evaluation, including (1) demand-side users (end users of the platform), (2) supply-side users (app developers on the platform) and (3) platform providers and sponsors (platform companies). However, the above research has not yet formed a complete and executable evaluation system. Finally, due to the various types of platforms and cooperation objects, it is necessary to classify typical cooperation structures (e.g. mixed retail, software compatibility) to better capture the cooperation characteristics of different modes.

6.2.2 The dynamic evolution of platform opening and cooperation modes. At present, it is only fragmented research based on practical observations, and the development dynamics of platform opening and cooperation have not been taken into consideration. As mentioned in Section 6.1, future research can use evolutionary games and longitudinal case studies to identify the evolutionary path of platform opening and cooperation to provide clearer management insights for platform development.

More importantly, we notice two frontier cooperation modes, which may generate some interesting research opportunities. On the one hand, the platform is evolving toward an ecosystem based on value co-creation. A platform ecosystem consists of a platform leader that designs and governs the technical architecture. Furthermore, it also consists of different groups of actors that interact on the platform: providers of complementary products and services to the platform (i.e. complementors) and users. The purpose of such an ecosystem is to enable joint value creation while guaranteeing effective value capturing for all participating actors (Schmeiss et al., 2019). In this case, future research can focus on the organization and operating mechanism of the platform ecosystem, including platform transaction rules, platform transaction order and the access of providers and users. On the other hand, cooperation between cross-type platforms is also a promising research direction. For example, an aggregation model has emerged in China, which means that a platform with Internet technology integrates the services of multiple third-party platforms. In Singapore, Alipay has also integrated ride-hailing services from mainstream ride-hailing platform Grab 
and taxi company ComfortDelGro (Chinadaily, 2017). At present, a few scholars have noticed this, such as the cooperation between the e-commerce platform and social platform (Liu et al., 2021a), and the cooperation between the food delivery platform and social platform (Zhu et al., 2021). Future research can use methods such as mathematical modeling and multiple case studies to explore the driving and potential impact of the above phenomena.

6.2.3 Potential crisis and impact of platform opening. Scholars generally believe that the opening and cooperation between platforms can bring mutual benefits to stakeholders. In fact, continued opening leads to some monopolistic platforms, which have created many scandals based on their dominant position in the ecosystem. For example, Google, Amazon, Facebook and Apple have been accused of abusing their market power to restrict competitors from entering the market (Rietveld and Schilling, 2021). Therefore, we also encourage scholars to study the potential crises that cooperation and opening bring to the platform system, and whether it affects the long-term development of the platform. In addition, many studies explore the conditions in which platforms can implement compatibility, but only a few studies analyze the outcomes of cooperation or opening. An important reason for the limited number of studies studying these outcomes and impacts lies in the dynamic nature of changes to platform opening (temporal effects, path dependencies) that complicates the establishment of cause-and-effect relationships. Most studies are therefore restricted to quasiexperimental designs by linking platform changes to its openness with longitudinal data on (performance) outcomes (Broekhuizen et al., 2021). Therefore, future research should take the time dimension into consideration. By tracking changes in platform opening and cooperative decision-making (e.g. channel availability, cooperation partners, service scope), scholars can correlate them with the platform's outcomes (user participation, user satisfaction, market share).

6.2.4 Governance of open platforms. Platform governance requires addressing several interdependent tensions, including the need to balance platform opening and control, exerting influence over the quality and range of complements, managing simultaneous collaboration and competition with complementors and creating ecosystem value while also capturing some of that value (Rietveld and Schilling, 2021). Scholars can focus on clarifying the responsibility and governance boundaries of the platform, and encourage platform participants to create value through more accurate incentives (Schmeiss et al., 2019). To be specific, they can set access standards based on value orientation to ensure that complementary participants interact and create value. In fact, we also encourage researchers to move away from isolated governance practices and explore their impact from a holistic perspective. For example, how does a platform's menu of governance practice change over time? Do different platforms manage their complementors and users differently, and if so, what is driving these differences? On this basis, will some new technologies, such as blockchain, help improve the platform governance performance? In addition to designing an open platform governance mechanism for platform owners, providing antitrust advice to government departments is also a future research opportunity. For example, how can the government prevent big data price discrimination by platforms against existing customers? And how to effectively protect user data and privacy information?

In conclusion, in this section, we analyze the limitations of existing research and propose four future research agendas, which we summarize as shown in Figure 9.

\section{Conclusions}

Platform economy is a hot topic in the field of operation management, but the research on platform opening and cooperation is a topic that has just emerged in recent years. To this end, we select 86 papers from 2010 to 2021 for a systematic review. We find that the above literature can be divided into three major categories according to the process of platform 
MSCRA

4,2

Figure 9.

Future research agendas

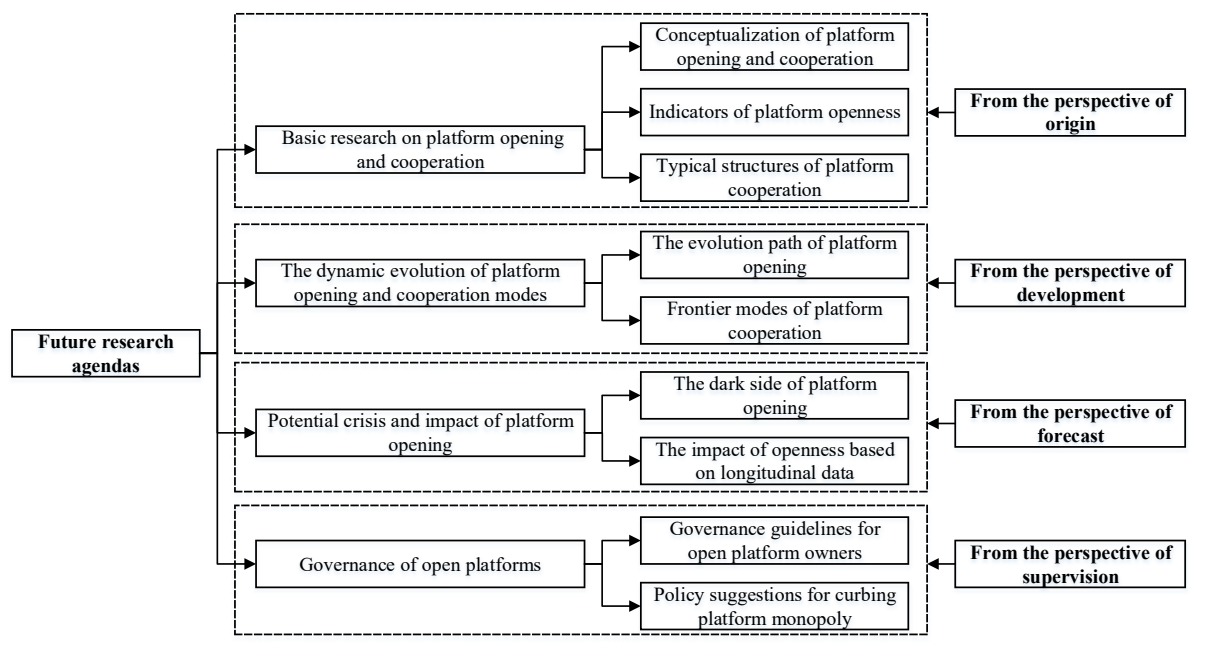

opening and cooperation: the strategic choice of platform opening and cooperation (before opening), the construction of an open platform (during opening) and the impact of platform opening and cooperation (after opening).

On this basis, we further sort out several subthemes for each theme. We find that nearly half of the studies focus on "the strategic choice of platform opening and cooperation." In contrast, the studies on "the construction of an open platform" and "the impact of platform opening and cooperation" account for about a quarter, respectively. In addition, with the development of platform operations, some new modes, such as platform ecosystems and platform governance, have emerged. In short, there is an urgent need for scholars to conduct exploratory research.

To this end, this review paper first puts forward some general recommendations, including paying attention to diverse research cases and industry backgrounds, and using more research methods. On this basis, we try to propose four research agendas for platform opening and cooperation. First, strengthen basic research on platform opening and cooperation, including the conceptualization of platform opening and cooperation, the design of open indicators and analysis of typical structures of platform cooperation. Second, future scholars can deeply explore the dynamic evolution of platform opening and cooperation modes. The operating mechanism of the platform ecosystem and the cooperation between cross-type platforms are also potential research opportunities. Third, the potential crisis and impact of platform opening deserve in-depth analysis. It is suggested that future scholars take the time dimension into consideration to better analyze the performance of platform opening. We also encourage exploring the dark side of platform opening. Finally, it is recommended that future scholars strengthen their research on the governance of open platforms.

\section{References}

Abbate, T., Codini, A.P. and Aquilani, B. (2019), "Knowledge co-creation in open innovation digital platforms: processes, tools and services", Journal of Business and Industrial Marketing, Vol. 34 No. 7, pp. 1434-1447.

Abbate, T., Codini, A., Aquilani, B. and Vrontis, D. (2021), "From knowledge ecosystems to capabilities ecosystems: when open innovation digital platforms lead to value co-creation", Journal of the Knowledge Economy, pp. 1-15. 
Abhishek, V., Jerath, K. and Zhang, Z.J. (2016), "Agency selling or reselling? Channel structures in electronic retailing”, Management Science, Vol. 62 No. 8, pp. 2259-2280.

Adner, R., Chen, J. and Zhu, F. (2020), "Frenemies in platform markets: heterogeneous profit foci as drivers of compatibility decisions", Management Science, Vol. 66 No. 6, pp. 2432-2451.

Armstrong, M. (2006), "Competition in two sided markets", The RAND Journal of Economics, Vol. 37 No. 3, pp. 668-691.

Bahar, V.S., Nenonen, S. and Starr, R.G. Jr (2022), "Coopetition with platforms: balancing the interplay of cooperation and competition in hospitality", Tourism Management, Vol. 88, p. 104417.

Bakos, Y. and Halaburda, H. (2020), "Platform competition with multihoming on both sides: subsidize or not?”, Management Science, Vol. 66 No. 12, pp. 5599-5607.

Boudreau, K. (2010), "Open platform strategies and innovation: granting access vs. devolving control”, Management Science, Vol. 56 No. 10, pp. 1849-1872.

Broekhuizen, T.L., Emrich, O., Gijsenberg, M.J., Broekhuis, M., Donkers, B. and Sloot, L.M. (2021), "Digital platform openness: drivers, dimensions and outcomes", Journal of Business Research, Vol. 122, pp. 902-914.

Chinadaily (2017), Singapore Taxis Connect to Alipay, available at: http://m.haiwainet.cn/middle/ 456236/2017/0822/content_31080874_1.html.

Chou, M.C., Sim, C.K., Teo, C.P. and Zheng, H. (2012), "Newsvendor pricing problem in a two sided market”, Production and Operations Management, Vol. 21 No. 1, pp. 204-208.

Cohen, M. and Zhang, R.P. (2017), "Competition and coopetition for two-sided platforms", available at: SSRN 3028138, doi: 10.2139/ssrn.3028138.

Cozzolino, A., Corbo, L. and Aversa, P. (2021), "Digital platform-based ecosystems: the evolution of collaboration and competition between incumbent producers and entrant platforms", Journal of Business Research, Vol. 126, pp. 385-400.

Esposito De Falco, S., Renzi, A., Orlando, B. and Cucari, N. (2017), "Open collaborative innovation and digital platforms”, Production Planning and Control, Vol. 28 No. 16, pp. 1344-1353.

European Commission (2017), "Online platforms", available at: https://ec.europa.eu/digital-singlemarket/en/policies/online-platforms (accessed 16 November 2017).

Fan, X., Yin, Z. and Liu, Y. (2020), "The value of horizontal cooperation in online retail channels", Electronic Commerce Research and Applications, Vol. 39, p. 100897.

Federal Trade Commission (2016), The 'sharing' Economy: Issues Facing Platforms, Participants, and Regulations, Staff report, Federal Trade Commission, Washington, DC.

Feng, Y., Tan, Y.R., Duan, Y. and Bai, Y. (2020), "Strategies analysis of luxury fashion rental platform in sharing economy", Transportation Research Part E: Logistics and Transportation Review, Vol. 142, p. 102065.

Gallino, S. and Moreno, A. (2014), "Integration of online and offline channels in retail: the impact of sharing reliable inventory availability information”, Management Science, Vol. 60 No. 6, pp. 1434-1451.

Geng, S., Ma, J., Wang, C. and Liu, F. (2021), "Multihoming vs. Single-homing software: compatibility or competition?”, IEEE Access, Vol. 9, pp. 24119-24132.

Hagiu, A., Jullien, B. and Wright, J. (2020), "Creating platforms by hosting rivals", Management Science, Vol. 66 No. 7, pp. 3234-3248.

Hahn, R. and Kühnen, M. (2013), "Determinants of sustainability reporting: a review of results, trends, theory, and opportunities in an expanding field of research", Journal of Cleaner Production, Vol. 59, pp. 5-21.

He, P., He, Y. and Xu, H. (2020), "Buy-online-and-deliver-from-store strategy for a dual-channel supply chain considering retailer's location advantage", Transportation Research Part E: Logistics and Transportation Review, Vol. 144, p. 102127.

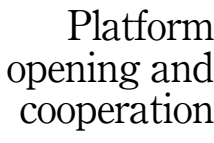


MSCRA

4,2

102

He, Y., Xu, Q. and Shao, Z. (2021), "Ship-from-store" strategy in platform retailing", Transportation Research Part E: Logistics and Transportation Review, Vol. 145, p. 102153.

Hilbolling, S., Berends, H., Deken, F. and Tuertscher, P. (2020), "Complementors as connectors: managing open innovation around digital product platforms", R\&D Management, Vol. 50 No. 1, pp. 18-30.

Hsiao, L. and Chen, Y.J. (2013), "The perils of selling online: manufacturer competition, channel conflict, and consumer preferences", Marketing Letters, Vol. 24 No. 3, pp. 277-292.

Huang, M. and Jin, D. (2020), "Impact of buy-online-and-return-in-store service on omnichannel retailing: a supply chain competitive perspective”, Electronic Commerce Research and Applications, Vol. 41, p. 100977.

Karhu, K., Gustafsson, R. and Lyytinen, K. (2018), "Exploiting and defending open digital platforms with boundary resources: android's five platform forks", Information Systems Research, Vol. 29 No. 2, pp. 479-497.

Kong, R., Luo, L., Chen, L. and Keblis, M.F. (2020), "The effects of BOPS implementation under different pricing strategies in omnichannel retailing", Transportation Research Part E: Logistics and Transportation Review, Vol. 141, p. 102014.

Kung, L. and Zhong, G. (2017), "The optimal pricing strategy for two-sided platform delivery in the sharing economy", Transportation Research Part E-Logistics and Transportation Review, pp. 1-12.

Lahiri, A., Dewan, R.M. and Freimer, M. (2010), "The disruptive effect of open platforms on markets for wireless services", Journal of Management Information Systems, Vol. 27 No. 3, pp. 81-110.

Lee, Y.W., Moon, H.C. and Yin, W. (2020), "Innovation process in the business ecosystem: the four cooperations practices in the media platform", Business Process Management Journal, Vol. 26 No. 4, pp. 943-971.

Li, Z. and Agarwal, A. (2017), "Platform integration and demand spillovers in complementary markets: evidence from Facebook's integration of Instagram”, Management Science, Vol. 63 No. 10 , pp. 3438-3458.

Li, Q., Wang, Q. and Song, P. (2019), "The effects of agency selling on reselling on hybrid retail platforms", International Journal of Electronic Commerce, Vol. 23 No. 4, pp. 524-556.

Lin, X., Sun, C., Cao, B., Zhou, Y.W. and Chen, C. (2021), "Should ride-sharing platforms cooperate with car-rental companies? Implications for consumer surplus and driver surplus", Omega, Vol. 102, p. 102309.

Liu, L., Feng, L., Xu, B. and Deng, W. (2020a), “Operation strategies for an omni-channel supply chain: who is better off taking on the online channel and offline service?", Electronic Commerce Research and Applications, Vol. 39, p. 100918.

Liu, W., Liang, Y., Wei, S. and Wu, P. (2020b), “The organizational collaboration framework of smart logistics ecological chain: a multi-case study in China”, Industrial Management and Data Systems, Vol. 121 No. 9, pp. 2026-2047.

Liu, W., Liang, Y., Tang, O., Shi, V. and Liu, X. (2021a), "Cooperate or not? Strategic analysis of platform interactions considering market power and precision marketing", Transportation Research Part E: Logistics and Transportation Review, Vol. 154, p. 102479.

Liu, W., Long, S., Wei, S., Xie, D., Wang, J. and Liu, X. (2021b), "Smart logistics ecological cooperation with data sharing and platform empowerment: an examination with evolutionary game model", International Journal of Production Research. doi: 10.1080/00207543.2021.1925173.

Lu, K., Zhou, J. and Lin, X. (2019), "Research on compatibility strategy of ride-hailing platforms", European Journal of International Management, Vol. 13 No. 6, pp. 880-906.

Ma, Y., Du, G. and Jiao, R.J. (2020), "Optimal crowdsourcing contracting for reconfigurable process planning in open manufacturing: a bilevel coordinated optimization approach", International Journal of Production Economics, Vol. 228, p. 107884. 
Mačiulienė, M. and Skaržauskienė, A. (2016), "Evaluation of co-creation perspective in networked collaboration platforms", Journal of Business Research, Vol. 69 No. 11, pp. 4826-4830.

Mantena, R. and Saha, R.L. (2012), "Co-opetition between differentiated platforms in two-sided markets", Journal of Management Information Systems, Vol. 29 No. 2, pp. 109-140.

Maruyama, M. and Zennyo, Y. (2015), “Application compatibility and affiliation in two-sided markets”, Economics Letters, Vol. 130, pp. 39-42.

Menon, K., Kärkkäinen, H. and Wuest, T. (2020), "Industrial internet platform provider and end-user perceptions of platform openness impacts", Industry and Innovation, Vol. 27 No. 4, pp. 363-389.

Niu, B., Li, Q., Mu, Z., Chen, L. and Ji, P. (2021), "Platform logistics or self-logistics? Restaurants' cooperation with online food-delivery platform considering profitability and sustainability", International Journal of Production Economics, Vol. 234, p. 108064.

Ondrus, J., Gannamaneni, A. and Lyytinen, K. (2015), "The impact of openness on the market potential of multi-sided platforms: a case study of mobile payment platforms", Journal of Information Technology, Vol. 30 No. 3, pp. 260-275.

Qin, X., Liu, Z. and Tian, L. (2020), "The strategic analysis of logistics service sharing in an ecommerce platform”, Omega, Vol. 92, p. 102153.

Ren, X., Herty, M. and Zhao, L. (2020), "Optimal price and service decisions for sharing platform and coordination between manufacturer and platform with recycling", Computers \& Industrial Engineering, Vol. 147, p. 106586.

Rietveld, J. and Schilling, M.A. (2021), "Platform competition: a systematic and interdisciplinary review of the literature", Journal of Management, Vol. 47 No. 6, pp. 1528-1563.

Ritala, P., Golnam, A. and Wegmann, A. (2014), "Coopetition-based business models: the case of Amazon. com”, Industrial Marketing Management, Vol. 43 No. 2, pp. 236-249.

Schmeiss, J., Hoelzle, K. and Tech, R.P. (2019), "Designing governance mechanisms in platform ecosystems: addressing the paradox of openness through blockchain technology", California Management Review, Vol. 62 No. 1, pp. 121-143.

Sohu News (2019), Didi Launches an Open Platform for Taxi-Hailing, Which Will Be Accessed by FAW, Dongfeng and GAC, available at: https://www.sohu.com/a/326940205_118792.

Song, W., Chen, J. and Li, W. (2020), "Spillover effect of consumer awareness on third parties' selling strategies and retailers' platform openness", Information Systems Research, Vol. 32 No. 1, pp. 172-193.

Tan, B., Anderson, E.G. Jr and Parker, G.G. (2020), "Platform pricing and investment to drive third-party value creation in two-sided networks", Information Systems Research, Vol. 31 No. 1, pp. 217-239.

Tian, L., Vakharia, A.J., Tan, Y. and Xu, Y. (2018), "Marketplace, reseller, or hybrid: strategic analysis of an emerging E commerce model", Production and Operations Management, Vol. 27 No. 8, pp. 1595-1610.

Tranfield, D., Denyer, D. and Smart, P. (2003), "Towards a methodology for developing evidence in formed management knowledge by means of systematic review", British Journal of Management, Vol. 14 No. 3, pp. 207-222.

Tsai, C.L. (2018), "The timing of fostering complementary innovation: exploring the antecedent of industry platform emergence", Technology Analysis and Strategic Management, Vol. 30 No. 10, pp. 1121-1135.

Van Alstyne, M.W., Parker, G.G. and Choudary, S.P. (2016), "Reasons platforms fail", Harvard Business Review, Vol. 31 No. 6, pp. 2-6.

Weber, A. and Maier, E. (2020), "Reducing competitive research shopping with cross-channel delivery", International Journal of Electronic Commerce, Vol. 24 No. 1, pp. 78-106.

Wei, R., Geiger, S. and Vize, R. (2019), "A platform approach in solution business: how platform openness can be used to control solution networks", Industrial Marketing Management, Vol. 83, pp. 251-265. 
MSCRA

4,2

\section{4}

Wessel, M., Thies, F. and Benlian, A. (2017), "Opening the floodgates: the implications of increasing platform openness in crowdfunding”, Journal of Information Technology, Vol. 32 No. 4, pp. 344-360.

Xiang, Z. and Xu, M. (2019), "Dynamic cooperation strategies of the closed-loop supply chain involving the internet service platform”, Journal of Cleaner Production, Vol. 220, pp. 1180-1193.

Yoshioka, T., Herman, G., Yates, J. and Orlikowski, W. (2001), "Genre taxonomy: a knowledge repository of communicative actions", ACM Transactions on Information Systems (TOIS), Vol. 19 No. 4, pp. 431-456.

Zhang, H., Dan, B. and Zhang, X. (2021a), "Discourage or encourage? An online manufacture's response to competing product introduction under physical showroom cooperation”, Electronic Commerce Research and Applications, Vol. 47, p. 101038.

Zhang, L., Chen, F., Xia, S., Cao, D., Ye, Z., Shen, C., Maas, G. and Li, Y. (2021b), "Value co-creation and appropriation of platform-based alliances in cooperative advertising", Industrial Marketing Management, Vol. 96, pp. 213-225.

Zhu, F. and Liu, Q. (2018), "Competing with complementors: an empirical look at Amazon. com", Strategic Management Journal, Vol. 39 No. 10, pp. 2618-2642.

Zhu, X., Yang, C., Liu, K., Zhang, R. and Jiang, Q. (2021), "Cooperation and decision making in a twosided market motivated by the externality of a third-party social media platform", Annals of Operations Research. doi: 10.1007/s10479-021-04109-w.

\section{Corresponding author}

Yanjie Liang can be contacted at: yanjie950929@qq.com

For instructions on how to order reprints of this article, please visit our website:

www.emeraldgrouppublishing.com/licensing/reprints.htm

Or contact us for further details: permissions@emeraldinsight.com 